\title{
Independent Study Workbooks for Proofs in Group Theory
}

\author{
Lara Alcock $^{1}$ - Gavin Brown ${ }^{2}$ - Clare Dunning ${ }^{3}$
}

Published online: 15 May 2015

(C) Springer International Publishing Switzerland 2015

\begin{abstract}
This paper describes a small-scale research project based on workbooks designed to support independent study of proofs in a first course on abstract algebra. We discuss the lecturers' aims in designing the workbooks, and set these against a background of research on students' learning of group theory and on epistemological beliefs and study habits in higher education. We organise our analysis of student responses around three emerging themes: 1) structured support provided by the workbooks, 2) productive forced study of lecture notes, and 3) engaging with proofs. Discussion of our data in terms of these themes suggests several considerations for the design of tasks for independent study of advanced mathematics.
\end{abstract}

Keywords Undergraduate mathematics · Textbooks · Reading comprehension · Task design · Proof comprehension · Study habits

Lara Alcock

L.J.Alcock@lboro.ac.uk

Gavin Brown

g.brown@warwick.ac.uk

Clare Dunning

t.c.dunning@kent.ac.uk

1 Mathematics Education Centre, Loughborough University, Loughborough LE11 3TU, UK

2 Mathematics Institute, University of Warwick, Coventry CV4 7AL, UK

3 School of Mathematics, Statistics and Actuarial Science, University of Kent, Canterbury, Kent CT2 7NZ, UK 


\section{Introduction}

"The thing I was setting out to do was to say, 'Look, in your notes there's a proof ... you can sit down for an hour and you can work hard to understand it. It looks like it's easy because it's four lines long. But, you know, actually you are going to have to spend ten minutes thinking about each line. And here is an example of how you take a proof like that, and you cut it into lines.' So that's, if you like, one way to read a proof, if you're not experienced in seeing, in knowing that each line actually is a substantial thing and is there for a reason."

Gavin Brown, lecturer and workbook designer

"I don't know how much study [students] do. Certainly in my courses I have the impression that some students do very little. [...] This is a conceptual course and I don't know how you could go to it and not have to study. [ ... ] You have to think about it. So these [workbooks], I think, give the opportunity ... a forced opportunity to sit down and think about it."

Clare Dunning, lecturer and workbook project collaborator

Learning abstract mathematics at the undergraduate level involves a lot of independent study. As lecturers we try to present material clearly and to assign problems that will help students to engage with it, but we often have little idea of how they go about their work outside the classroom. Setting regular problem sheets might provide information about how well students can apply standard results and methods, but we are less likely to find out whether and how they go about trying to understand proofs given in lectures. Often the only sense we have of this comes from disappointing examination attempts that lead us to believe that students do not typically succeed in understanding presented proofs.

With this in mind, we discuss a project that aimed to direct students' attention to the proofs in an undergraduate abstract algebra module. The second author, as the lecturer of this module, together with the third author, designed two workbooks to help students work effectively during their independent study. The workbooks and the research context are described after the Theoretical Background section, and a short workbook sample and a link to both workbooks can be found in the Appendix. In the second year of workbook use, the two lecturers invited the first author to investigate the students' experience of the workbooks; this investigation is reported here.

We report our main findings regarding students' experience ${ }^{1}$ of the workbooks in the Methods and Results section. In brief, the participants reported that:

(1) The structure provided by the workbooks helped them to work independently on abstract material including proofs in algebra;

(2) The workbooks promoted careful study of the lecture notes (in some cases, study that would not otherwise have taken place);

\footnotetext{
${ }^{1}$ We focus on students' experience of working with the unusual workbook resource rather than on course outcomes after its use. The institution in question has only one cohort studying abstract algebra per year, workbook use had developed and been adjusted in the preceding years (see also the Workbook Content and Structure section), and our study was not extensive enough to include a comparative component across years.
} 
(3) The tasks in the workbooks helped them to analyse proofs in ways they had not done before.

We relate our comments throughout to themes from the research literature as discussed in the Theoretical Background section, which begins with issues in learning and moves on to research-based responses to identified problems. The report concludes with a brief discussion of the way in which the issues raised might influence thinking about task design for abstract mathematical subjects in general.

\section{Theoretical Background}

\section{Research on Learning Group Theory}

Group theory is an abstract topic involving formal definitions, theorems and proofs. It involves technical concepts such as cosets and isomorphisms, for which research indicates that students might be able to perform some relevant calculations but less able to think at higher levels of abstraction. For instance, a student might be able to perform standard processes to find cosets in specific groups, but find it difficult to treat a coset as an object that can itself be a member of a quotient group (Dubinsky et al. 1994; Leron and Dubinsky 1995). Similarly, a student might try to establish whether two groups are isomorphic by checking computationally simple properties such as group and element orders, despite being able to list relevant global properties such as commutativity and cyclicity (Leron et al. 1995). Various researchers have reported cases in which students became stuck during attempts to construct an isomorphism when these involved some choice about how to proceed (Leron et al. 1995; Weber and Alcock 2005).

As an abstract subject, group theory is also open to misconceptions at the more general levels of proof and logical reasoning. Weber (2001) found that undergraduate students were often unable to prove non-trivial group theoretic propositions, even when they had the requisite knowledge. They apparently lacked strategic knowledge possessed by doctoral students who were able to quickly identify, for instance, cases in which the first isomorphism theorem would help. One clear case of problems with logic was reported by Hazzan and Leron (1996), in which students misapplied Lagrange's theorem to conclude that $\mathbb{Z}_{3}$ is a subgroup of $\mathbb{Z}_{6}$ because 3 divides 6 . As Hazzan pointed out, "students not only confuse Lagrange's theorem with its converse (If $k \mid o(G)$, then there exists in $G$ a subgroup of order $k$-which is not a true statement), but actually use an incorrect version of the converse statement (If $o(H) \mid o(G)$ then $H$ is a subgroup of $G$ )" (Hazzan 1999, p.78).

\section{Research on Reading Proofs}

Issues of logic are involved in applying theorems but also in understanding and validating proofs, which are arguably more common tasks for students in standard lecture courses (Mejía-Ramos et al. 2012; Hodds et al. 2014). Selden and Selden (1995) argued that one cannot reliably decide whether a proof proves a given theorem 
without being able to accurately "unpack the logic" of theorem statements, and reported a study in which undergraduates on a transition-to-proof course were asked to validate purported proofs. They found that, at a first pass, the students' judgments of validity were no better than chance, and others have reported similar results (Selden and Selden 2003; Alcock and Weber 2005; Weber 2009; Inglis and Alcock 2012). Weber (2009) reported that undergraduates rarely spent more than five minutes trying to understand a proof, were sometimes prepared to make validity judgments while acknowledging that they did not have a full understanding, and often believed that anything that would help understanding should be provided rather than generated by the reader. Weber and Mejía-Ramos (2014) extended this work, establishing that beliefs consistent with these behaviours were common among a larger sample of undergraduates.

Research has also indicated that students tend to focus more on checking local details or algebraic manipulations than on understanding the global structures of proofs: on this point, evidence from eye-movement studies (Inglis and Alcock 2012) is in line with that from observational studies (Selden and Selden 2003; Weber 2009; Shepherd et al. 2012; Shepherd and van de Sande 2014). Indeed, it has been suggested that the presence of mathematical symbols might cue comparatively ineffective reading strategies (Österholm 2008). More broadly, it is well recognised that academic texts in general present challenges to the novice reader (Snow and Uccelli 2009; Snow 2010). Doubtless there is variation among student approaches: Weber et al. (2008) found that stronger students were more likely when reading to reformulate definitions, connect new concepts to existing knowledge, and try to understand theorem and exercise statements before moving on. But many mathematics students might be accustomed to treating texts primarily as sources of exercises and examples rather than as expository texts that can support understanding (Barton and Heidema 2000; Randahl 2012; Weinberg et al. 2012). These points are of particular relevance since the workbooks discussed in this paper were designed to encourage students to read the expository sections of their notes and to attend in detail to why each line of a proof is valid.

\section{Research on Study Habits and Beliefs}

In higher education in general, considerable work has been done on students' study habits and beliefs about learning. Perry's work, for instance, characterised the development of students' epistemological beliefs during the college years (Perry 1970), from "dualistic" beliefs in right and wrong answers and the authority of the teacher, to a "relativistic" perspective involving a better understanding of critical comparison of ideas (Perry 1988). Copes (1982) considered this in relation to undergraduate mathematics learning, discussing ways in which different types of task might make sense for students with different beliefs while allowing them to grow toward a more sophisticated perspective.

Others have focused more on the mechanics of learning. Marton and Säljö’s work, initially characterising surface and deep approaches to studying sections from a textbook (Marton and Säljö 1976), has been widely influential. Various terminologies have been used for this or similar distinctions (see e.g. Hofer and Pintrich 1997) 
but Ramsden gave the following summary characterisations, intended to apply in the context of everyday academic studying.

A student who adopts a deep approach has an intention to understand and to:

- focus on "what is signified" (e.g. the author's argument, or the concepts applicable to solving the problem);

- relate previous knowledge to new knowledge;

- relate knowledge from different courses;

- relate theoretical ideas to everyday experience;

- relate and distinguish evidence and argument;

- $\quad$ organise and structure content into a coherent whole.

In contrast, a student who adopts a surface approach has an intention only to complete task requirements and to:

- focus on "the signs" (e.g. the words and sentences of the text, or unthinkingly on the formula needed to solve the problem);

- focus on unrelated parts of the task;

- memorise information for assessments;

- associate facts and concepts unreflectively;

- fail to distinguish principles from examples;

- treat the task as an external imposition.

(Ramsden 2003, p.47)

Many authors have used such characterisations in both large-scale surveys and more detailed interviews, refining them in different contexts (e.g., Entwistle and Ramsden 1983; Kember 1996; Richardson 1990; Vermunt 1998) and examining, for example, relationships between different approaches and academic performance (e.g., Rodriguez and Cano 2006). Of particular interest here are findings that there appears to be a two-way relationship between a high perceived workload and a surface approach (Kember 2004; Richardson 2007). As noted above, lecturers generally know little about the amount of time students spend studying; in mathematics this does not appear to have been widely investigated, though Lawless (2000) found that in Open University distance-taught courses in mathematics and computing, students reported that the time needed to "make a serious effort to solve" problems often exceeded the notional 10-15 hours per week. This issue is not straightforward: Kember and Leung reported that perceived workload is only weakly related to actual study time (Kember and Leung 2006). But it is important in the UK climate where increasing numbers of students are undertaking paid work alongside their studies (Moreau and Leathwood 2006). Indeed, for some of our student participants, one major concern was whether the set work helped them to use their study time effectively. The workbook designer was keen that the students should not feel overloaded, but we did not know at the outset how much time it would take for students to complete the workbooks so we collected this information as part of our study.

\section{Research on Student Beliefs About Mathematics}

There are obvious relationships between the study habits and epistemological beliefs discussed above and those found among mathematics students (e.g., Muis 2004). Some can be seen in Schoenfeld's list of common student views about mathematics: 
- Mathematics problems have one and only one right answer;

- There is only one correct way to solve any mathematics problem-usually the rule the teacher has most recently demonstrated to the class;

- Mathematics is a solitary activity, done by individuals in isolation;

- The mathematics learned in school has little or nothing to do with the real world;

- Formal proof is irrelevant to the processes of discovery or invention.

(Schoenfeld 1992, p.359)

Similar beliefs have been found in large scale qualtitative and quantitative studies. Crawford et al. (1994) used a phenomenographic study involving 300 beginning university students in Australia to develop a categorisation of conceptions of mathematics. They found that the majority (77\%) had a fragmented conception (as opposed to a cohesive conception) in which they viewed mathematics as a set of rules and procedures, and took a surface approach to learning that focused on rote memorisation and doing lots of examples with the intention of reproducing knowledge and procedures. They developed a Conceptions of Mathematics Questionnaire (CMQ) and found a significant positive correlation between the Fragmented Conception scale and the Surface Approaches to Study scale from Biggs' Study Process Questionnaire (Crawford et al. 1998). Mji (2003) used the CMQ in studies involving 459 first year mathematics students in South Africa, and classified $54 \%$ as having fragmented conceptions and following a "reproducing" (as opposed to "meaning") orientation to study as measured by Richardson's Approaches to Studying Inventory (ASI) (Richardson 1990). From the point of view of proof-based mathematics this is problematic because, although a student might survive in earlier mathematics courses by practising and memorising procedures that they do not understand well, this approach will not be viable in a course in which there are few repeated procedures and the focus is shifted toward understanding and constructing general arguments.

Given the apparent prevalence of such fragmented conceptions of mathematics and surface approaches to study, we have to recognise that development toward deep approaches and more mature epistemological beliefs might be challenging. Changing beliefs is a slow process that may generate insecurity (e.g., Copes 1982), and merely giving advice on productive study strategies will not necessarily have the desired effect: recognising that an alternative approach is effective is no guarantee that a person will take it up (Gibbs 1981). It is also possible that much current school and university mathematics teaching mitigates against movement in a positive direction. According to Gueudet (2008), mathematics at the secondary level is often encountered as a set of task types and associated techniques, with limited opportunity for the student to integrate these into broader mathematical organisations that are linked at the theoretical level. Both Hardy (2009) and Barbé et al. (2005) present specific studies of institutional factors meaning that students may interpret their learning experience in this way, even if this is not the articulated intent at the syllabus level. At university, in "pure hard" sciences, teachers tend to concentrate on how to structure content in a way that is easier for students to understand rather than on how to facilitate construction of individual knowledge and understanding (Lindlbom-Ylänne et al. 2006). As a result, teaching tends to involve presentation by authority rather than 
participation in the development of knowledge through the formulation of conjecture, argument and proof (e.g., Solomon 2006).

For the learner, teacher-centred lectures are compatible both with dualistic beliefs about knowledge and with a surface approach to study; Hayes and Richardson (1995) found that compared with arts students, science students had higher reproducing orientations. Of course, it is not clear whether students' approaches are driven by the teaching or whether students self-select into science courses because of their existing beliefs-Perry alludes to the latter possibility (Perry 1970, p.90). But research suggests that teacher-centred presentations can alienate students who are beginning to develop and express their individual identities in other parts of their lives (Boaler and Greeno 2000; Solomon 2007). Either way, students who believe that mathematics is a set of techniques to be memorized and who rely on external authorities to provide answers are not likely to engage spontaneously in the type of detailed study of proofs and reasoning that we would like to see, so we have reason to believe that tasks that deliberately promote such study may be appropriate.

\section{Research-Based Responses}

In response to the issues outlined above, researchers have conducted studies in classrooms in which the social and sociomathematical norms (Yackel et al. 2000) give students more opportunity to act as legitimate peripheral participants in a community of practice (in the sense of Lave and Wenger 1992; see also Solomon 2007). Such classrooms typically involve students in constructing and validating mathematical knowledge by explaining their reasoning and attempting to make sense of each other's explanations, in small group or whole class discussions (e.g., Yackel et al. 2000). Some researchers have developed curricula for undergraduate topics based around this type of environment, including a group theory course that uses a "guided reinvention" approach (Larsen and Zandieh 2008; Weber and Larsen 2008; Zandieh et al. 2008; Johnson and Larsen 2012; Larsen 2013).

Emphases on student discussion have also featured in other non-standard instructional approaches. Dubinsky and his colleagues stressed discussion and reflection as an important component of their APOS-based study (e.g., Asiala et al. 1996), and Alcock and Simpson (2001) reported on an analysis course in which students reconstructed the majority of the proofs for themselves by working in small groups through workbooks based on Burn's book Numbers and Functions (Burn 1992). The latter inspired the workbooks described in this paper, although here we see them used as assignments rather than lecture replacements.

Studies of alternative pedagogies generally report some success in enabling students to develop a more solid, experience-based understanding of the abstract mathematics than might be found after a typical lecture course (e.g., Asiala et al. 1997; Larsen 2013). However, the fact remains that these curricula have typical been implemented only with small classes (perhaps 20-30 students), and that in many cases in many countries, larger classes place severe restrictions on the use of such different teaching methods. Even where small classes are possible, traditional lecturer-centred teaching styles tend to persist. 
Other researchers have suggested approaches that can more easily be incorporated into traditional lecture courses, and these are similar in ethos and sometimes in practice to the approach reported here. Conradie and Frith (2000), for instance, described the construction and use of proof comprehension questions as part of mathematics courses and examinations; Cowen (1991) made a similar argument about the importance of teaching mathematical reading. Shepherd (2005) developed structured reading guides to help students read their college mathematics textbooks effectively, and Hodds et al. (2014) reported that students who received a short course of generic self-explanation training showed improved comprehension of mathematical proofs. The workbooks described here are based similarly on the idea that students might benefit from guidance in reading mathematical text; like the instruction developed by Conradie and Frith and Shepherd, they use questions specific to particular text content.

\section{Summary}

In all, mathematics lecturers are faced with lecture classes likely to include students with a variety of epistemological beliefs and learning approaches. Lecturers hope to help all of them to engage deeply with the mathematics on offer, to develop their understanding of abstract concepts and to improve their ability to understand and construct proofs. Many would like to promote an atmosphere of mathematical investigation in lectures, but are restricted by class sizes or by limited experience of alternative pedagogies. Where everyone has flexibility, however, is in assigning tasks for students to complete outside the classroom. The module discussed here, as is common in the UK, devoted over half of the notional learning time to study outside lectures. Without wanting to assign workloads that encourage unproductive approaches, lecturers have considerable leeway in what we actually want students to spend this study time doing. The remainder of this paper discusses how a particular, non-standard type of assignment might support the kind of engagement and learning that we want to see.

\section{Research Context}

\section{The UK Undergraduate Degree Programme}

We carried out our study in an algebra module called Groups, Rings and Fields, which was taken by second-year students as part of a three-year undergraduate mathematics degree at a UK university. The department in which it was offered has around 35 mathematics students among an annual cohort of 150 students on other mathematically-related degrees. Teaching occurs during two 12-week terms with examinations in summer, and students take eight modules per year. In the first year, mathematics students study geometry, calculus, differential equations, algebra, 
discrete mathematics, probability, statistics, and mathematical computing. ${ }^{2}$ In the second year, analysis and linear algebra modules are compulsory, and students take six more modules from eight available. Groups, Rings and Fields is one of these options, and most mathematics students take this module, usually going on to study the topics further in third year algebra.

\section{Module Structure, Content and Assessment}

The module was taught in three 1-hour lectures per week. These lectures were "traditional" in that students took notes from the board with only small amounts of student-lecturer or student-student interaction. The module also had a weekly 1-hour problems class, in which the students worked in groups on pre-distributed problems with some assistance from the lecturer. In the term in which this study took place, 25 students were registered for the module. Typical attendance was around 19-23 students during lectures, slightly fewer for the problems class.

The module was broken into four main blocks in its 12-week lecture series: groups, rings, group homomorphisms and ring homomorphisms. The final examination was worth $80 \%$ of the credit; it required students to complete six questions from ten in two hours, where a typical question asked for a definition, an elementary calculation, a guided portion of proof and an unseen consequence. The remaining credit came from four coursework assignments, each worth $5 \%$. These were submitted during the term and students were given around a week to complete them-this allowed notionally 6 hours of independent work for each assignment. Two of the assignments were standard problem sheets comprising 4-5 questions; the remaining two were the workbooks.

\section{Workbook Content and Structure}

The workbooks each reviewed the major ideas of one of the first two topics: the first was on Lagrange's theorem, the second on factorisation in integral domains. We studied students' approaches to both workbooks, although we report here only on the first (hereafter referred to as "the workbook"). The workbook was divided into six sections: Lagrange's theorem, Cosets, Cosets have the same size, Cosets partition the group, The proof of Lagrange's theorem, and Case study: subgroups of the isometry group of the square. The 2-page first section, included here as an Appendix, gives a good idea of the workbook design, although some of the later sections included more explicit calculations. One aim of the workbook design was that amid the lecture notes, students would become familiar and comfortable with a few small "islands"

\footnotetext{
${ }^{2}$ In the UK students specialise earlier than in some countries, so that a mathematics degree may involve only mathematics modules (although there is often some freedom in later years for taking outside options from other subjects).
} 
of difficult material; also that certain key points, such as definitions, would be reinforced and, if necessary, corrected. As Brown put it, the workbooks "are set-pieces ... each one of them is self-contained, given that you know one or two things. You can't function in [workbook 1] if you don't know the definition of a group, but there's not much more that you need."

Historically, the workbooks had been developed and used in slightly different ways over the preceding years. Originally, the workbook on Lagrange's theorem was intended to reinforce and then expand on material that had been lectured, since this was usually the part of the course that students found most difficult or even out of reach. In this early use, Brown gave two standard first lectures on cosets and Lagrange's theorem and the following two lectures were set aside to give additional time for students to work through the workbook. The initial sections covered the same definitions and elementary results as the lectures, while the exercises were new and the final case study section was unseen. Although success with the case study was an indication of progress for students, in some ways the recapitulation was the most valuable part, for it was there that a set-piece proof or definition delivered in a lecture was decomposed by the student rather than the lecturer. In later years, including that in which this study took place, the workbooks were used primarily to give students ideas about how to analyse an abstract proof from their lecture notes during their independent study time, not as initial sources for teaching new material.

\section{Methods and Results}

The research study proceeded as follows.

(1) The first author interviewed the two remaining authors independently, discussing their aims for the workbooks. ${ }^{3}$ The responses were used to construct a feedback form that all students on the module would complete.

(2) Four sets of students, two individuals and two pairs, were video-recorded while working for their first hour on the workbook (the students were asked not to begin until they arrived). Notes were made on numerical data from the observations, such as the time participants spent working on each question.

(3) Alcock interviewed the observed students, as individuals or in their pairs, immediately after this hour's work. The interviews were transcribed and the students' comments coded.

(4) Feedback form responses from all students on the module were collated.

In the following sections we discuss the method and outcome of each phase. Our main data comes from phases 3 and 4 .

\section{Lecturer Interviews}

In audio-recorded interviews, the lecturers were each asked to describe

\footnotetext{
${ }^{3}$ These interviews are the source of the lecturer quotes throughout this paper.
} 
- the background to designing the workbooks;

- the content and structure of the workbooks, including the relationship of these to the lecture notes and the practicalities of the course;

- what they hoped the students would learn by working on the workbooks, about the mathematical content and about proof and proving in general.

The interviews were structured around these points, with many additional questions for clarification. Notes were made on each interview, and the comments were broken down into two types: those about the structure of the module and programme, and those about the aims of the workbooks and the research. Further analysis of the second type led to a draft of the student feedback form. The final version of this form, along with responses to it, are shown in the Workbook Feedback Forms section.

\section{Student Observations}

Our aim in the observations was to capture the way in which the students would work under normal circumstances. Obviously the location and recording would be different, but we asked for volunteers to come alone or in pairs according to their usual practice. The students were asked not to begin the workbook before they arrived, so that we would see everyone working on it for the first time. The observations used a small office, with two webcams set up so that one faced the student(s) and one recorded what they were writing. The first author watched both of these feeds live and made extensive notes about what the students appeared to be focusing on throughout the hour's observation. All participants indicated that the camera may have altered their behaviour slightly (as a minor distraction at first and, in the case of the pairs, preventing them from messing around to some extent) but all asserted that they did not think it had altered their mathematical behaviour.

Table 1 shows how many minutes the students spent working on which parts of the workbook (a blank cell indicates zero time). The table also shows the participants' scores for each workbook and for the final module examination, along with their overall scores in year 1 and year 2 modules. The table shows the variety of ways in which these students used their time. Most worked through the workbook in order from the beginning, only skipping occasional parts where they were stuck. Penny, however, adopted a different strategy, commenting later,

P: I make sure I've got it, or if I recognise it, and then I'll just move on, because there's no point me spending time on it when I maybe try something that I find more difficult and need to spend more time on. I'd rather do the harder things and leave the easier things for when, maybe, it's due in a day later.

\section{Student Interviews}

In each post-observation interview, the participating students were asked the following questions.

- Please tell me about your general experience of working on that workbook.

- Do you have any comments about specific parts of it? 
Table 1 Time (in minutes) spent on different workbook tasks during the observation, with score data

\begin{tabular}{|c|c|c|c|c|}
\hline & Kelly & Liam \& Mick & Nathan \& Oscar & Penny \\
\hline Intro/reading/organising & 6.5 & 10 & 7.5 & 2 \\
\hline 1.2 Lagrange app & 11 & 20 & 40.5 & 11.5 \\
\hline 2.2 golden rule & 8 & 7.5 & 6 & 3 \\
\hline 2.2 computing cosets & 4.5 & 3.5 (skip) & & 19 \\
\hline 2.3 representatives & 1.5 & 6 & & 2.5 \\
\hline 3.1 cosets same size & 3 & 1.5 (skip) & & 1.5 (skip) \\
\hline 4.1 computing cosets & 4 & 8 & & 2 \\
\hline 4.1 partitions & 2 & & & 2 \\
\hline 4.2 union of cosets & 1.5 & & & 5 (skip) \\
\hline \multicolumn{5}{|l|}{5 Lagrange proof } \\
\hline \multicolumn{5}{|l|}{6 Isom(sq) } \\
\hline 6.3 Isom(sq) lattice & & & & 8 \\
\hline Workbook score & 90 & $55 \& 90$ & $70 \& 75$ & 75 \\
\hline Module exam score & 75 & $58 \& 56$ & $40 \& 62$ & 78 \\
\hline Year 1 average & 73.4 & $52.8 \& 54.8$ & $50.0 \& 43.4$ & 67.5 \\
\hline Year 2 average & 66.6 & $39.6 \& 54.8$ & $47.1 \& 57.1$ & 61.9 \\
\hline
\end{tabular}

- Was it different from ordinary study you would do for this module? If so, how?

- Have you learned or understood anything that you didn't know or understand before?

These questions were open and general to allow the participants to describe whatever aspects of the experience seemed pertinent to them. They also avoided attracting attention to the lecturers' aims for the workbooks, so as not to influence students in their continued work. After this part of the interview, the interviewer used her observation notes as a basis for asking about the students' specific work, including points at which they appeared to get stuck, questions that they decided to miss out, what they were looking for when they looked in their notes, and so on.

The interviews were transcribed, and Alcock wrote descriptive open codes (in the sense of Strauss and Corbin 1990) to capture the essence of the students' statements. These were sorted into general issues about undergraduate mathematics and three emergent themes that pertain specifically to the experience of the workbooks:

- structured support provided by the workbooks;

- forced, productive study of lecture notes;

- engaging with proofs.

These themes, arising directly from the students' experience of the workbook, constitute the main result of our study. We now give details from the interviews to explain what they mean. 


\section{Structured Support Provided by the Workbooks}

The interviewees spoke positively of the workbook structure and the fact that it allowed them to feel relatively confident in tackling this work. Kelly, Liam, Penny and Oscar all remarked on the fact that the workbooks helped them know where to start and where to look in their lecture notes.

$K$ : I quite like these workbooks because I kind of ... you get a little bit of information first and not just the question, so it's putting you in the right sort of ... starting to think about it. Whereas sometimes you just pick up a question and go, I have no idea what this relates to.

$L:$... in all the other modules you get like, it'll just have like question 1, question 2, question 3, question 4, and it'll literally say "prove this", and it's just like, well where the hell do I get this from? But that tells you what chapter, where you get it from, so you can work through it and you learn a lot more doing that. Because otherwise it's just like having a stab in the dark.

$P:$...it's just usually about one thing, for the whole assessment. And you don't obviously get any lead-ins at all, you just get a question. Left to figure it out yourself.

$O$ : I thought it was quite good. Because, because of the fact that you've like got all the information, already there. Well, a lot of it anyway. You can ...you've still got to look through your notes as well, but you've got quite a lot of the information already there.

The workbook structure also appeared to support students in developing and maintaining confidence that they were progressing and learning appropriately. Oscar and Mick commented:

$O$ : Because it got sort of set out bit by bit, I felt like I could kind of like, well I felt like I could actually do it. I felt like I was actually getting somewhere.

M: I know that once I've done that, underneath it tells you, like it doublechecks what you've done, so you're like oh I know I'm right, so you ... you learn. Whereas otherwise if I'm doing a whole question thing, and I'm not sure if that's right or not, you don't take it in, because you don't think you're right.

These comments indicate that the students often did not feel able to identify relevant parts of their notes without explicit direction, or to judge for themselves whether their own reasoning was correct. As a result, they appreciated the recapitulated material and the structure of the workbook. As a lecturer, one might find this reliance on external direction and evaluation to be disappointing and an indicator of a surface approach to study, but it does highlight an aspect of the student experience that may go unaddressed by standard problem sheets.

\section{Forced, Productive Study of Lecture Notes}

The second major theme to emerge from the interview analysis was that the workbooks promoted study of the lecture notes. For some, such study was a regular part 
of their work: Kelly and Penny both said that they read their notes regularly, though Penny indicated that the workbooks promoted what might be considered "deeper" study.

$P$ : Well it asks me questions, whereas, when I read my notes, I'll just, I'll just go through it. Sometimes I'll look up something if I'm unsure about it, but it's not-reading doesn't force me to do anything. Whereas if I'm doing that, it forces me to actually look into everything if I have a problem. Rather than, oh I think I've got a problem, but I'll leave it.

For the remaining students, the workbook clearly led to some interaction with the lecture notes that would not otherwise have taken place. When asked whether they read through their notes when not working on coursework, Liam's, Mick's and Nathan's responses were:

M: Yeah a little bit, but not often.

L: No. I'll organise them, like when I get my sheet out I'll organise them. But I won't like, read through it, recapping or whatever.

$N$ : Er ... I haven't really had time to be honest. Because we started this just after Christmas, and I've got so many assessments going on at the moment, I don't really get time to read through my notes very often.

Perhaps more importantly, the workbooks were seen to promote productive use of study time in comparison with other types of work (the remarks above about knowing where to start are also relevant to this issue). Liam and Mick were the most vociferous on this topic, comparing the workbook experience positively with their common experience of wasting time when attempting coursework. Mick commented that it was often the case that "the questions don't resemble any examples that we've done." When the interviewer (denoted "I:") proposed that a lecturer might think that students would learn more if they had to read their notes carefully and to work out where to start, the following conversation ensued.

L: But it wastes time. Big time. I mean, I've spent-another one I've spent like a good four hours on a piece of coursework, not being able to find it. And it's like, that's not really very productive. [ . . The workbooks are] not like baby food, it's not like spoon-feeding you, it's just giving you the push. Because it's like, once you've got the knowledge, you can then do it again.

I: I see. So you don't feel like, from that time looking through your notes, you're really learning anything when you're not finding what you need?

L: Exactly. You get frustrated.

M: You're looking for a certain thing so you're not taking in anything else. You kind of look at it and you think, I don't need this, so you just go right, and get it out of your head.

Penny said much the same thing in a more measured way, commenting that the workbook changed the way she read her notes. 
$P$ : Because like I'll be skipping bits, and I won't actually be reading all theI won't go through the whole notes. Whereas this really does make you go through all of them. Instead of flick, flick, flick.

Many of these comments suggest that Dunning's observation in the introduction was not that wide off the mark: some of these students were not reading their notes unless specifically attempting coursework. Again, this raises questions about the difference between what a lecturer might ideally expect students to do and what they actually do.

\section{Engaging with Proofs}

The last theme focuses on students' perceptions of what they learned in relation to mathematical proofs. In general the participants could see the need to engage with definitions and proofs in mathematics at this level, and they were fairly articulate in expressing their own relative inexperience and inadequacy in this respect.

$N:$...the actual questions you get, like exam-style, they are to recite proofs and ... it's-I don't think it's ... well it's just that I'm less experienced at doing that. I mean last year the modules, basically, were mostly like doing exercises. Learning a method and doing it, sort of thing.

$K$ : I don't think I'm ever going to be brilliant at writing proofs. I will keep trying, but ... you kind of just see, kind of teasing out to put more information down, or in a better way than, maybe than we did in the past. But it's not going to happen in one workbook.

$N$ : Like I could say it in English, why the generated group is equal to the size of the other group, but I didn't know how to put it down, on paper. Which is something I do struggle with.

P: I'm not very good on definitions sort of, like this. I can explain it in my own words, but not actually, in symbolic. Like if I was explaining something with, a few lines.

The students varied somewhat in their opinions about the requirement to break down proofs into steps and consider each in detail. Kelly stressed the fact that the workbook prompted her to think more carefully and give more information than she otherwise would about why deductions within proofs are valid. In the excerpt below she was discussing a question that set up $\psi_{g}(h)=g h$ and required showing that if $\psi_{g}\left(h_{1}\right)=\psi_{g}\left(h_{2}\right)$ then $h_{1}=h_{2}$. In her answer she had written "left cancellation $\left(\times g^{-1}\right)$ "; she said

$K$ : ... if it had just said, show that they're equal, you'd have just gone, well it's obvious. Whereas, because they've kind of ... prodded you in the right direction, it's like, well you know that's the answer, so you have to show why it's the answer.

Oscar found it useful that the workbook helped in breaking proofs down in this way. 
$O$ : Because, sometimes ... you can get intimidated by a big proof, I think. [ ... ]

I: So you found that helpful in that respect.

$O$ : Yeah. Yeah definitely.

Nathan was more equivocal about this requirement to break a proof down and give more explanation for each line for each line:

$N$ : I found it hard because I found it kind of pointless. [ ... ] I think it helps you understand it because you can work out-like you can do your own little proofs of ... little bits. But, that's something I would come back to like ... later.

However, he did report that "I would be able to go through the proof again and write it down again" without referring to notes. This is an interesting point because Nathan studied his notes (on the application of Lagrange's theorem) a great deal during the observation time, and considered the proof from his notes as a whole rather than trying to break it up for the workbook. However, one might also say that the workbook nonetheless had a substantial influence, since his earlier comments make it seem unlikely that he would have put in this study otherwise.

The interviews also provided evidence of the extent to which it might be laborious for students to identify the reason for a step in a proof. A vivid illustration of this is provided by Kelly. In describing uncertainty about one of her answers she said,

$K$ : It [the claim] says [ ...] that $G$ is a subset of the union of all cosets. [ ...]

So, I should have written something to that effect in there [the corresponding box]. But all it says is that if $g$ is an element of $G$, then there is some coset that contains $g$. Which isn't the same.

Of course, it is the same, since if every $g$ in $G$ is in one of the cosets, then $G$ is contained in the union of the cosets. The fact that Kelly did not apparently see this highlights the need students might have for support in understanding the detail of proofs. Nonetheless, Kelly and all the other students were able to engage with the questions. All worked consistently during the observation time, writing notes either in the workbooks or on separate paper and, in the case of the pairs, discussing and debating their reasoning. Certainly much of what the students submitted in the completed workbooks was correct mathematics, as evidenced by their eventual workbook scores.

\section{Workbook Feedback Forms}

21 students completed the feedback form. The responses to questions about the learning experience are summarised in Table 2 . The responses were generally positive, with the highest averages for improved understanding of the material and the proofs, and the lowest for likelihood of remembering the proofs and confidence in reading, understanding, reproducing and constructing proofs in general. Of course, it is not possible to conclude anything about students' absolute level of understanding from this information. However, the students made reasonable attempts to complete the workbook: scores awarded for the workbook ranged from $55 \%$ to $96 \%$ with a mean 
Table 2 Self-reports on the learning experience

\begin{tabular}{|c|c|c|c|c|c|c|}
\hline After working on this workbook ... & SD & $\mathrm{D}$ & $\mathrm{N}$ & A & SA & mean \\
\hline $\begin{array}{l}\text { I have a better understanding of the } \\
\text { material. }\end{array}$ & & & & 16 & 5 & 4.24 \\
\hline $\begin{array}{l}\text { I am more likely to remember the } \\
\text { material correctly. }\end{array}$ & & & 2 & 14 & 5 & 4.14 \\
\hline $\begin{array}{l}\text { I have a better understanding of the } \\
\text { relationships between the mathematical ideas. }\end{array}$ & & & 4 & 16 & 1 & 3.86 \\
\hline $\begin{array}{l}\text { I have a better understanding of the } \\
\text { overall structure of this part of the course. }\end{array}$ & & & 2 & 13 & 6 & 4.19 \\
\hline $\begin{array}{l}\text { I have a better understanding of the } \\
\text { proofs. }\end{array}$ & & & 2 & 12 & 7 & 4.24 \\
\hline $\begin{array}{l}\text { I am more likely to remember the } \\
\text { proofs. }\end{array}$ & & 1 & 7 & 10 & 3 & 3.71 \\
\hline $\begin{array}{l}\text { I have taken proofs apart line-by-line } \\
\text { in a way that I had not before. }\end{array}$ & & 1 & 7 & 8 & 5 & 3.81 \\
\hline $\begin{array}{l}\text { I will take other proofs apart line-by-line } \\
\text { like this in future. }\end{array}$ & & & 8 & 9 & 4 & 3.81 \\
\hline $\begin{array}{l}\text { I am more confident that I can read and } \\
\text { understand proofs in general. }\end{array}$ & & 2 & 6 & 8 & 5 & 3.76 \\
\hline $\begin{array}{l}\text { I am more confident that I can reproduce } \\
\text { and construct proofs in general. }\end{array}$ & & 1 & 10 & 8 & 2 & 3.52 \\
\hline
\end{tabular}

of $82 \%$, which was above the overall average coursework mark of $78 \%$. We also note that the majority of the students indicated that they had not previously broken down proofs in the way that the workbook required.

The feedback form also sought information on study time by asking:

$\mathrm{H}$ How many hours did you spend on this workbook?

O For how many of the hours did you work with other students?

$\mathrm{N}$ For how many of the hours did you actively refer to your lecture notes?

Responses from the 19 students who gave numerical answers are summarized in Figs. 1 and 2, which show the total times these students spent on the workbook (in descending order) and the proportions of their total time that they spent working with other students and actively referring to lecture notes.

The students reported spending an average of about 5 hours on the workbook, with about 1.5 hours spent working with others and about 3 hours spent referring to notes. However, it would be misleading to think of this as a breakdown for a typical student, as there is considerable variation in the proportion of time spent that involved working with others (ranging from $0 \%$ to $83 \%$ with five students working entirely alone) or actively referring to notes (ranging from $20 \%$ to $100 \%$ ). It is encouraging that the overall times listed by the respondents were well within the limit estimated by the lecturer (10 hours' study for the week, including lecture time). 


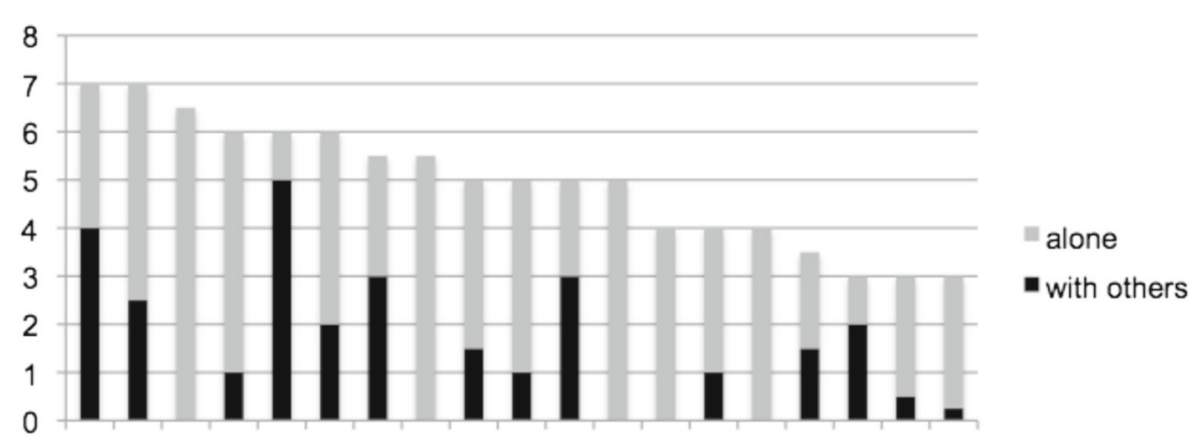

Fig. 1 Total times (in hours) spent on the workbook and proportion working with others

\section{Discussion and Implications for Task Design}

Our small study found that the aims of the workbook designers, which were not explicitly shared with the students, were addressed in the students' comments. Brown had hoped that the workbooks would help students to dissect proofs when working independently, and Dunning had hoped that they would encourage students to devote time to conceptual work. The observations and the three themes that emerged from the interviews indicate that both hopes were reasonable: although we saw considerable variation in how much our participants managed during their observation time (with those who were not in the habit of studying their notes making less progress), all were able to engage with the questions and to formulate responses. The themes also suggested that students can enjoy and feel a benefit from tightly-structured workbooks, and that such workbooks can promote a deeper approach in tasks undertaken during independent study time. The participants all reported a positive experience of the workbook, not least because they felt that it promoted more careful study of the notes, and did so in a way that allowed them to use their study time productively (only one student from the course used the usual anonymous module feedback process to say that she or he did not like the workbook).

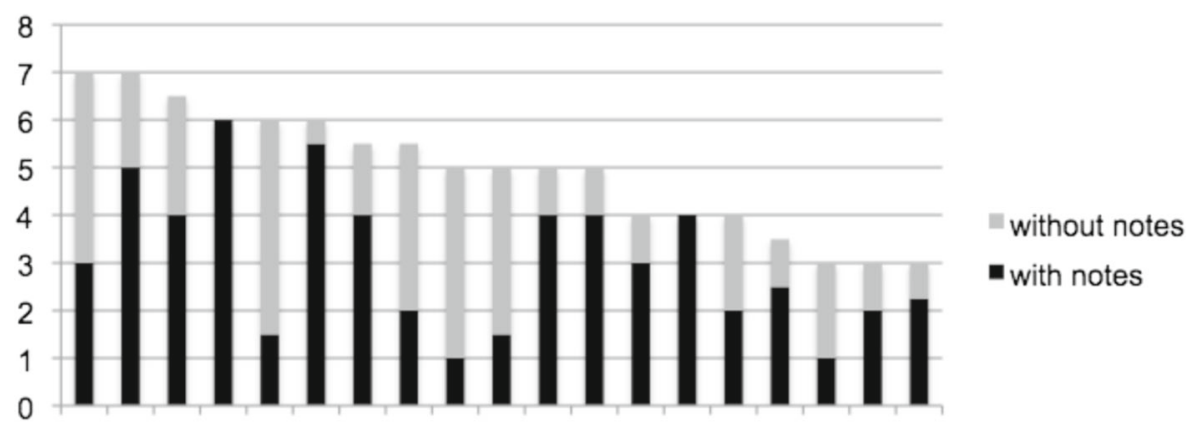

Fig. 2 Total times (in hours) spent on the workbook and proportion referring to notes 
Our observations and interviews also supported the commonly-held views we discussed in the Theoretical Background section: that learning group theory is hard because the concepts are abstract and because it involves reading and writing proofs, and that students come to the task with a variety of learning practices and beliefs about knowledge. The participants acknowledged their own difficulties in dealing with abstract proofs and, in some cases, that they did not ordinarily spend time studying their lecture notes.

We certainly do not suggest that workbooks like this can solve the problems of learning abstract mathematics, but for us this research raised two general questions about setting work for independent study. First, to what extent can material from lecture notes usefully be recapitulated, or at least closely referenced, on task sheets? The workbooks discussed here gave large amounts of review and direction. One might believe that this ought to be unnecessary, but such support might mean that when students do study they can at least spend their time productively. Second, to what extent can we design tasks that promote detailed reading of proofs? Typical calculation exercises do not necessarily address this. One might expect that students would undertake extended study of proofs for themselves, but our participants' comments were in keeping with the broader literature in suggesting that this cannot be taken for granted. In "guided discovery" courses the problem is addressed by radically altering the classroom norms (Zandieh et al. 2008; Larsen 2013) but, like other researchers (Conradie and Frith 2000; Shepherd 2005), we believe that it possible also to include tasks that support study of proofs as an accompaniment to a traditional course.

Both of the above questions could be seen crudely as addressing how much we are prepared to compensate for students' poor study habits. But we could also ask, do students know what to do even if they do put in the hours? Studying proof-based mathematics is a new type of task, quite different from many students' previous mathematical experience. It may therefore be that typical courses demand that students learn new abstract mathematics and simultaneously acquire the study skills needed to interact with it. This is a tall order, and perhaps it is worth providing at least a temporary structure in which students can interact with their notes productively. It might seem patronising to go too far in this direction, but it is clear that the students in this study did not experience the workbooks as over-prescriptive. Naturally, any such support requires careful consideration: the development of the materials necessarily comes at the expense of increased investment of a lecturer's time and, as Mason observed, one can fall into the trap of doing more and more for students because it seems expedient (Mason 2002, p.23). As such, although the questions above clarify some of the issues of independent study, there is bound to be variation in the way in which lecturers respond to them. Workbooks such as those discussed here are not the only possible answer, and more generic guidance might also be effective (Hodds et al. 2014). Nevertheless we are encouraged by the student response and we conclude that it does seem possible to construct tasks that effectively support independent study of abstract mathematical proofs.

Acknowledgments This project was supported by a grant from the Mathematics, Statistics and Operations Research subject centre of the Higher Education Academy.

We thank the reviewers and editor for helpful suggestions and comments on an earlier draft. 


\section{Appendix A: Workbook Sample}

Both workbooks are available online at www.kent.ac.uk/smsas/personal/tcd/webpages/msor/index.html

The text here shows the opening pages of the workbook discussed in this paper.

\section{Cosets and Lagrange's Theorem}

\section{Lagrange's Theorem}

Lagrange's theorem is about finite groups and their subgroups. It is very important in group theory, and not just because it has a name.

Theorem 1 (Lagrange's theorem) Let $G$ be a finite group and $H \subset G$ a subgroup of $G$. Then $|H|$ divides $|G|$.

We will prove this theorem later in the workbook. But first we begin to see what the theorem means.

\section{Understanding the Statement}

Remember that $|G|$ denotes the number of elements of the group $G$; it makes perfect sense because $G$ is finite. Similarly, since $H \subset G$, certainly $H$ is also finite and again writing $|H|$ makes sense.

Now Lagrange's theorem says that whatever groups $H \subset G$ we have, $|H|$ divides $|G|$. That's an amazing thing, because it's not easy for one number to divide another. For example, if we had a group $G_{1}$ with $\left|G_{1}\right|=77$, then any subgroup of $G_{1}$ could only have size $1,7,11$ or 77 . So if you were working out the elements of a subgroup $H_{1}$ of $G_{1}$ and you could see 12 different elements of $H_{1}$ already, then in fact you would be finished: you would know that $\left|H_{1}\right|=77$, and so the subgroup would have to be the whole of $G$.

That example is a bit artificial. Nevertheless, seeing how a theorem is used in practice helps you to understand it, so we look next at a true application of Lagrange's theorem.

\section{A Favourite Application of Lagrange's Theorem}

The same counting argument as above (but easier) proves your favourite first corollary of Lagrange's theorem. Remember that 2 is the smallest prime- 1 is not a prime.

Corollary 2 If $G$ is a finite group with $|G|$ prime, then $G$ is cyclic.

Proof Step 1: Show that $|G| \geq 2$ and conclude that there is some element $g \in G$ which is not equal to the identity $1_{G}$. 
Step 2: Using $g$ from Step 1, show that the subgroup $H=\langle g\rangle \subset G$ also has $|H| \geq 2$.

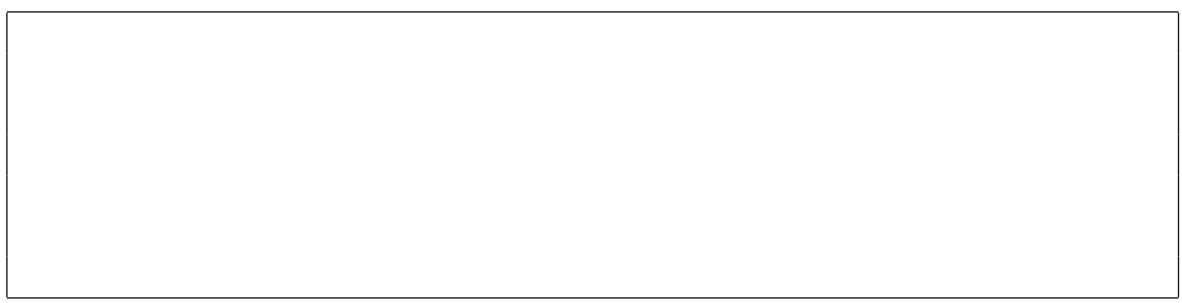

Step 3: Since $|G|$ is prime, conclude from Lagrange's theorem that $|H|=|G|$.

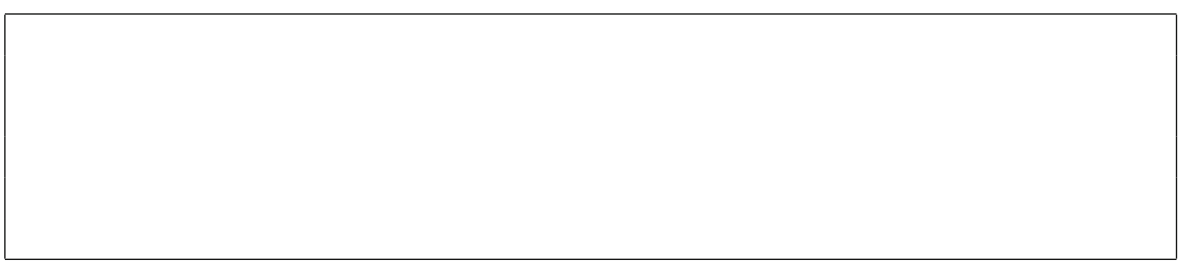

Step 4: Conclude that $\langle g\rangle=G$.

Step 5: Write down the definition of cyclic group (from lecture notes or a textbook), and conclude from the definition that $G$ is cyclic as claimed. 
We worked that proof out in very close detail. I write it out again much more briefly below-it's merely a condensed version of what you wrote above. The two versions of the proof are equally valid since they follow the same logical course and address the same mathematical points. You can decide which you prefer to read and which you prefer to write for yourself.

Proof (of Corollary 2 again) Let $p=|G|$. Since $p \geq 2$, there is an element $g \in G$ with $g \neq 1_{G}$. Consider the subgroup $\langle g\rangle \subset G$ generated by $g$. We have $|\langle g\rangle| \geq 2$ since both $1_{G}, g \in\langle g\rangle$. So by Lagrange's theorem $|\langle g\rangle|=p$. Thus $\langle g\rangle=G$, and so, by definition, $G$ is cyclic as claimed.

We will prove Lagrange's theorem over the next few sections. We start by defining cosets, since they will be the main technical tool.

\section{References}

Alcock, L., \& Simpson, A. (2001). The warwick analysis project: Practice and theory. In Holton, D. (Ed.) The teaching and learning of mathematics at the undergraduate level (pp. 99-112). Dordrecht: Kluwer.

Alcock, L., \& Weber, K. (2005). Proof validation in real analysis: Inferring and checking warrants. Journal of Mathematical Behavior, 24, 125-134.

Asiala, M., Brown, A., DeVries, D., Dubinsky, E., Matthews, D., \& Thomas, K. (1996). A framework for research and curriculum development in undergraduate mathematics education. In Research in Collegiate Mathematics Education II (pp. 1-32). Washington, DC: American Mathematical Society.

Asiala, M., Dubinsky, E., Matthews, D.W., Morics, S., \& Oktac, A. (1997). Development of students' understanding of cosets, normality, and quotient groups. Journal of Mathematical Behavior, 16, 241309.

Barbé, J., Bosch, M., Espinoza, L., \& Gascón, J. (2005). Didactic restrictions on the teacher's practice: The case of limits of functions in Spanish high schools. Educational Studies in Mathematics, 59, 235-268.

Barton, M.L., \& Heidema, C. (2000). Teaching Reading in Mathematics (2nd ed.) Washington, DC: Office of Educational Research and Improvement.

Boaler, J., \& Greeno, J. (2000). Identity, agency and knowing in mathematics worlds. In Boaler, J. (Ed.) Multiple perspectives on mathematics teaching and learning (pp. 171-200). Westport, CT: Ablex Publishing Corp.

Burn, R.P. (1992). Numbers and functions: Steps into analysis. Cambridge: Cambridge University Press.

Conradie, J., \& Frith, J. (2000). Comprehension tests in mathematics. Educational Studies in Mathematics, 42, 225-235.

Copes, L. (1982). The Perry development scheme: A metaphor for learning and teaching mathematics. For the Learning of Mathematics, 3(1), 38-44.

Cowen, C. (1991). Teaching and testing mathematics reading. American Mathematical Monthly, 98, 5053.

Crawford, K., Gordon, S., Nicholas, J., \& Prosser, M. (1994). Conceptions of mathematics and how it is learned: The perspectives of students entering university. Learning and Instruction, 4, 331-345.

Crawford, K., Gordon, S., Nicholas, J., \& Prosser, M. (1998). University mathematics students' conceptions of mathematics. Studies in Higher Education, 23, 87-94.

Dubinsky, E., Dautermann, J., Leron, U., \& Zazkis, R. (1994). On learning fundamental concepts of group theory. Educational Studies in Mathematics, 27, 267-305.

Entwistle, N., \& Ramsden, P. (1983). Understanding student learning. London: Croom Helm.

Gibbs, G. (1981). Teaching students to learn: A student-centred approach. Milton Keynes: Open University Press.

Gueudet, G. (2008). Investigating the secondary-tertiary transition. Educational Studies in Mathematics, 67, 237-254. 
Hardy, N. (2009). Students' perceptions of institutional practices: The case of limits of functions in college level calculus courses. Educational Studies in Mathematics, 72, 341-358.

Hayes, K., \& Richardson, J.T.E. (1995). Gender, subject and context as determinants of approaches to studying in higher education. Studies in Higher Education, 20, 215-221.

Hazzan, O. (1999). Reducing abstraction level when learning abstract algebra concepts. Educational Studies in Mathematics, 40, 71-90.

Hazzan, O., \& Leron, U. (1996). Students' use and misuse of mathematical theorems: The case of Lagrange's theorem. For the Learning of Mathematics, 16(1), 23-26.

Hodds, M., Alcock, L., \& Inglis, M. (2014). Self-explanation training improves proof comprehension. Journal for Research in Mathematics Education, 45, 62-101.

Hofer, B.K., \& Pintrich, P.R. (1997). The development of epistemological theories: Beliefs about knowledge and knowing and their relation to learning. Review of Educational Research, 67, 88-140.

Inglis, M., \& Alcock, L. (2012). Expert and novice approaches to reading mathematical proofs. Journal for Research in Mathematics Education, 43, 358-390.

Johnson, E.M.S., \& Larsen, S. (2012). Teacher listening: The role of knowledge of content and students. Journal of Mathematical Behavior, 31, 117-129.

Kember, D. (1996). The intention to both memorize and understand: Another approach to learning? Higher Education, 31, 341-354.

Kember, D. (2004). Interpreting student workload and the factors which shape students' perceptions of their workload. Studies in Higher Education, 29, 165-184.

Kember, D., \& Leung, D.Y.P. (2006). Characterising a teaching and learning environment conducive to making demands on students while not making their workload excessive. Studies in Higher Education, 29, 165-184.

Larsen, S. (2013). A local instructional theory for the guided reinvention of the group and isomorphism concepts. The Journal of Mathematical Behavior, 32, 712-725.

Larsen, S., \& Zandieh, M. (2008). Proofs and refutations in the undergraduate mathematics classroom. Educational Studies in Mathematics, 67, 185-198.

Lave, J., \& Wenger, E. (1992). Situated learning: Legitimate peripheral participation. Cambridge: Cambridge University Press.

Lawless, C. (2000). Using learning activities in mathematics: Workload and study time. Studies in Higher Education, 25, 97-111.

Leron, U., \& Dubinsky, E. (1995). An abstract algebra story. American Mathematical Monthly, 102, 227242.

Leron, U., Hazzan, O., \& Zazkis, R. (1995). Learning group isomorphism: A crossroads of many concepts. Educational Studies in Mathematics, 29, 153-174.

Lindlbom-Ylänne, S., Trigwell, K., Nevgi, A., \& Ashwin, P. (2006). How approaches to teaching are affected by discipline and teaching context. Studies in Higher Education, 31, 285-298.

Marton, F., \& Säljö, R. (1976). On qualitative differences in learning 1. British Journal of Educational Psychology, 46, 4-11.

Mason, J. (2002). Mathematics teaching practice: A guide for university and college lecturers. Chichester: Horwood Publishing.

Mejía-Ramos, J.-P., Fuller, E., Weber, K., Rhoads, K., \& Samkoff, A. (2012). An assessment model for proof comprehension in undergraduate mathematics. Educational Studies in Mathematics, 79, 3-18.

Mji, A. (2003). A three-year perspective on conceptions of and orientations to learning mathematics of prospective teachers and first year university students. International Journal of Mathematical Education in Science and Technology, 34, 687-698.

Moreau, M.-P., \& Leathwood, C. (2006). Balancing paid work and studies: Working (-class) students in higher education. Studies in Higher Education, 31, 23-42.

Muis, K.R. (2004). Personal epistemology and mathematics: A critical review and synthesis of research. Review of Educational Research, 74, 317-377.

Österholm, M. (2008). Do students need to learn how to use their mathematics textbooks?: The case of reading comprehension. Nordisk Matematikkdidaktikk, 13(3), 53-73.

Perry, W.G. (1970). Forms of intellectual and ethical development in the college years: A scheme. New York: Holt, Rinehart and Winston.

Perry, W.G. (1988). Different worlds in the same classroom. In Ramsden, P. (Ed.) Improving learning: New perspectives (pp. 145-161). London: Kogan Page.

Ramsden, P. (2003). Learning to teach in higher education. Abingdon: RoutledgeFalmer. 
Randahl, M. (2012). First-year engineering students' use of their mathematics textbook - opportunities and constraints. Mathematics Education Research Journal, 24, 239-256.

Richardson, J.T.E. (1990). Reliability and replicability of the approaches to studying questionnaire. Studies in Higher Education, 15, 155-168.

Richardson, J.T.E. (2007). Variations in student learning and perceptions of academic quality. In Entwistle, N., \& Tomlinson, P. (Eds.) Student learning and university teaching (pp. 61-72). Leicester: The British Psychological Society.

Rodriguez, L., \& Cano, F. (2006). The epistemological beliefs, learning approaches and study orchestrations of university students. Studies in Higher Education, 31, 617-636.

Schoenfeld, A.H. (1992). Learning to think mathematically: Problem solving, metacognition and sense making in mathematics. In Grouws, D. (Ed.) Handbook of research on mathematics teaching and learning (pp. 334-370). New York: Macmillan.

Selden, A., \& Selden, J. (2003). Validations of proofs considered as texts: Can undergraduates tell whether an argument proves a theorem? Journal for Research in Mathematics Education, 34(1), 4-36.

Selden, J., \& Selden, A. (1995). Unpacking the logic of mathematical statements. Educational Studies in Mathematics, 29, 123-151.

Shepherd, M.D. (2005). Encouraging students to read mathematics. Problems, Resources, and Issues in Mathematics Undergraduate Studies, 15, 124-144.

Shepherd, M.D., Selden, A., \& Selden, J. (2012). University students' reading of their first-year mathematics textbooks. Mathematical Thinking and Learning, 14, 226-256.

Shepherd, M.D., \& van de Sande, C.C. (2014). Reading mathematics for understanding-from novice to expert. The Journal of Mathematical Behavior, 35, 74-86.

Snow, C.E. (2010). Academic language and the challenge of reading for learning. Science, 328, 450-452.

Snow, C.E., \& Uccelli, P. (2009). The challenge of academic language. In Olson, D.R., \& Torrance, N. (Eds.) The Cambridge handbook of literacy (pp. 112-133). Cambridge: Cambridge University Press.

Solomon, Y. (2006). Deficit or difference? The role of students' epistemologies of mathematics in their interactions with proof. Educational Studies in Mathematics, 61, 373-393.

Solomon, Y. (2007). Not belonging? What makes a functional learner identity in undergraduate mathematics? Studies in Higher Education, 32, 79-96.

Strauss, A.C., \& Corbin, J. (1990). Basics of qualitative research: Techniques and procedures for developing grounded theory. Newbury Park, CA: Sage Publications Inc.

Vermunt, J.D. (1998). The regulation of constructive learning processes. British Journal of Educational Psychology, 68, 149-171.

Weber, K. (2001). Student difficulty in constructing proofs: The need for strategic knowledge. Educational Studies in Mathematics, 48, 101-119.

Weber, K. (2009). Mathematics majors' evaluation of mathematical arguments and their conception of proof. In Proceedings of the 12th SIGMAA on RUME Conference on Research in Undergraduate Mathematics Education. Raleigh, NC.

Weber, K., \& Alcock, L. (2005). Using warranted implications to understand and validate proofs. For the Learning of Mathematics, 25(1), 34-38.

Weber, K., Brophy, A., \& Lin, K. (2008). Learning advanced mathematical concepts by reading text. In Proceedings of the 11th Annual Conference on Research in Undergraduate Mathematics Education. San Diego, CA.

Weber, K., \& Larsen, S. (2008). Teaching and learning abstract algebra. In Carlson, M., \& Rasmussen, C. (Eds.) Making the connection: Research and teaching in undergraduate mathematics (pp. 139152). Washington, DC: MAA.

Weber, K., \& Mejía-Ramos, J.P. (2014). Mathematics majors' beliefs about proof reading. International Journal of Mathematical Education in Science and Technology, 45, 89-103.

Weinberg, A., Wiesner, E., Benesh, B., \& Boester, T. (2012). Undergraduate students' self-reported use of mathematics textbooks. PRIMUS, 22, 152-175.

Yackel, E., Rasmussen, C., \& King, K. (2000). Social and sociomathematical norms in an advanced undergraduate mathematics course. Journal of Mathematical Behavior, 19, 275-287.

Zandieh, M., Larsen, S., \& Nunley, D. (2008). Proving starting from informal notions of symmetry and transformations. In Carlson, M., \& Rasmussen, C. (Eds.) Making the connection: Research and Teaching in Undergraduate Mathematics (pp. 275-287). Washington, DC: MAA. 